\title{
LAS SOCIEDADES ARRENDATARIAS DE LOS IMPUESTOS MUNICIPALES DE VALENCIA (1410-1450)*
}

\author{
EnRiQue Cruselles Gómez \\ Universitat de València
}

\begin{abstract}
Resumen
La ciudad de Valencia había consolidado su sistema fiscal a finales del siglo XIV. El arrendamiento de los impuestos indirectos desempeñó un papel clave en ese sistema, mediante un procedimiento de subasta pública. Durante la primera mitad del siglo XV, se confirmaron dos procesos relacionados: la monopolización de los arrendamientos por parte de una élite financiera, que a la vez retenía los cargos contables municipales; y la tendencia a la baja de los precios de los arrendamientos, en detrimento del sistema económico municipal. La combinación de documentación pública y privada permite ampliar el conocimiento sobre la organización de aquellas sociedades arrendatarias.
\end{abstract}

\section{Palabras clave}

Sociedad urbana; élites financieras; empresas mercantiles; arrendamientos de impuestos; fiscalidad municipal.

\begin{abstract}
The city of Valencia consolidated its tax system at the end of the fourteenth century. Tax farming of indirect taxes played a key role in that system, being assigned through a public auction procedure. During the first half of the fifteenth century, two related processes were confirmed: the monopolization of tax revenue collection by a financial elite, which also held the municipal accounting offices, and the downward trend of tax rental prices, to the detriment of municipal economy. The combination of public and private documentation enables us to broaden our knowledge of the organization of those tax farming companies.
\end{abstract}

\section{Key words}

Urban society; financial elites; commercial companies; tax farming; municipal taxation.

\section{Résumé}

La ville de Valence a fini de consolider son système fiscal à la fin du XIVe siècle. L'affermage des impôts indirects a joué un rôle-clé dans ce système, par le biais d'une procédure d'adjudication publique. Au cours de la première moitié du $X V^{\mathrm{e}}$ siècle, deux phénomènes annexes se sont imposés au détriment du système économique municipal: la monopolisation de la ferme par une élite financière, qui en même temps a retenu à son profit les charges de la comptabilité municipale, et la tendance à la baisse

* Este trabajo se integra en el proyecto I+D+I Inquisición y sociedades urbanas. Los tribunales de Valencia, Teruel y Cuenca entre los siglos XV-XVI, subvencionado por el Ministerio de Ciencia e Innovación (HAR2012-34444). Correo electrónico: Enrique.Cruselles@uv.es. 
des revenus des perceptions. En recoupant la documentation publique avec la documentation privée, il a été possible d'approfondir nos connaissances sur l'organisation de ces sociétés adjudicataires.

\section{Mots clefs}

Société urbaine; élites financiéres; sociétés commerciales; affermage; fiscalité municipale.

Recuperada la ciudad de los estragos de mediados del siglo XIV y superadas las rivalidades que habían resquebrajado la cohesión del grupo patricio en el tránsito a la siguiente centuria, las reformas institucionales introducidas tras el ascenso de la dinastía Trastámara y la consolidación del mercado local en la red comercial europea favorecieron la estabilidad de un sistema político urbano cuya dinámica se vinculó a los variados mecanismos de reproducción económica de la oligarquía. Con esos cambios, la sociedad política local demostró su naturaleza elitista, quedando las decisiones de gobierno en manos de un restringido número de magistraturas relevantes, unas ejecutivas, otras técnicas, que fueron acaparadas de manera endogámica por un limitado grupo de familias ${ }^{1}$.

En las primeras décadas del siglo XV se concretó la organización definitiva de las finanzas municipales, etapa final de un proceso iniciado medio siglo antes ${ }^{2}$. Para entonces, la sociedad política había renunciado finalmente a la fiscalidad directa como instrumento de financiación de las necesidades comunales. El sistema fiscal urbano se apuntaló sobre dos elementos: la deuda pública, a través de la venta recurrente de censales, mecanismo más efectivo en la atracción de capitales y directamente vinculado a la reproducción económica de la oligarquía dirigente ${ }^{3}$; y, en segundo lugar, la fiscalidad indirecta, ligada a los intereses económicos del grupo financiero-mercantil, que permitía repercutir sobre el conjunto de la sociedad local el coste de la implementación de las políticas municipales. A lo largo de las décadas centrales del siglo, la relación entre ambos instrumentos financieros se mantuvo siempre a favor del segundo que solo se vio igualado coyunturalmente por la emisión de nueva deuda pública, cuando necesidades puntuales exigieron el endeudamiento del municipio ${ }^{4}$.

\footnotetext{
Rafael Narbona Vizcaíno, "Cultura política y comunidad urbana: Valencia, siglos XIV-XV”, Edad Media. Revista de Historia, 14 (2013), pp. 173-213.

2 Antoni Furió Diego, "Deuda pública e intereses privados. Finanzas y fiscalidad municipales en la Corona de Aragón", Edad Media. Revista de Historia, 2 (1999), pp. 35-79.

3 Más aún desde que los magistrados municipales, ante el revuelo social creado por algunos predicadores moralistas, obtuvieron del papa Martín V en 1430 una bula que declaraba los censales con carta de gracia ajenos a cualquier práctica usuraria, con lo que se acallaba la mala conciencia de la oligarquía compradora de censales y el descontento de los que se vieron obligados a endeudarse por necesidad, y cuyas demandas, inflamadas por la oratoria de los predicadores, producían en opinión de las autoridades municipales "gran dan a les universitats de aquest regne e encara als singulars, per ço com no poden haver diners sinó per via de vendes e carregaments de censals" (José María Cruselles Gómez, Els notaris de la ciutat de València. Activitat professional i comportament social a la primera meitat del segle XV, Fundació Noguera, Barcelona, 1988, pp. 356-357).

4 Si se analizan los datos expuestos en la nota 6 , que recogen cuatro sondeos realizados en los años fiscales 1437, 1446, 1459 y 1469, se obtiene la siguiente proporción: en años que pueden considerarse normales en cuanto a las necesidades financieras de la ciudad (1437 y 1459) entre el 60 y $65 \%$ de los ingresos municipales procedían de los arrendamientos de impuestos, mientras que la venta de nuevos censales superaba
} 
Paralelamente al afianzamiento de los mecanismos financieros, la hacienda municipal adquirió su organización definitiva. Fracasado el intento de crear una única banca pública centralizada, la Taula de canvis, en 1416 se tomó la decisión de escindir la función tesorera municipal en dos oficinas: una Claveria Comuna, que asumiría el control de los gastos ordinarios del municipio; y una Claveria de Censals, destinada a gestionar el pago de los intereses originados por la venta de deuda pública. Dos años antes, se había creado otra comisión, la del Quitament, cuyos capítulos fueron reformados en las décadas siguientes, y cuya función era costear la amortización de la deuda más antigua, suponiendo su gestión la creación de una tercera oficina contable ligada a esa institución, la Claveria del Quitament. Desde entonces, las tres claverías separadas se financiaron con el reparto de los ingresos procedentes del arrendamiento de los impuestos, de la venta de deuda y de la recuperación de los capitales adeudados al municipio por terceros ${ }^{5}$. El orden del reparto de la financiación de las claverías revela las preocupaciones y los intereses de la oligarquía dirigente. En los capítulos del Quitament de 1434 se explicita: primero, la tesorería destinada a la amortización de la deuda debía recibir una tercera parte de la imposición de la mercancía y la mitad del gravamen de la carne, más mil libras extraordinarias para subvenir a sus necesidades; en segundo lugar, la clavería de censales recibiría todos los ingresos procedentes de los impuestos indirectos que necesitara para hacer frente al pago de las pensiones censalistas más una cantidad recaudada con la emisión de nueva deuda; en último lugar, la clavería general o comuna emplearía los ingresos restantes. En la práctica, esta última tesorería se financió anualmente con la emisión de nuevos censales, cargados según se presentaban las necesidades al municipio ${ }^{6}$. Esto viene a confirmar que el presupuesto

por poco el $10 \%$; mientras que en otros ejercicios, como 1446 y 1469 , cuando los ingresos totales de las tres claverías casi duplicaron a los de los años anteriormente mencionados, la relación entre los dos tipos de ingresos tendió a equilibrarse: en 1446, el $41 \%$ procedían de los arrendamientos, el $48 \%$ de la emisión de deuda pública; en 1469, el 43\% y el 34\% respectivamente.

5 Salvador Carreres Zacarés, Libre de memòries de diversos sucesos e fets memorables e de coses senyalades de la ciutat e regne de Valencia (1308-1644), Acción Bibliográfica Valenciana, València, vol. I, 1930 , pp. 465 y 489.

6 En 1446 era clavario de los censales el mercader Joan Amat. En su contabilidad consignaba unos ingresos de 561.000 sueldos procedentes de los arrendatarios de los impuestos y de 65.501 sueldos entregados por el baile general para el pago de las pensiones de los censales que debía afrontar la Corona. Por su parte, el mercader Joan Castellano, clavario del dinero común, apuntaba 120.000 sueldos ingresados de los arrendatarios, más un total de 973.478 sueldos recibidos de la venta de deuda pública. En tercer lugar, Lluís Blanch, clavari del quitament, anotaba los siguientes ingresos: 152.280 sueldos procedentes de cuatro imposiciones y 161.133 sueldos por el cobro de deudas contraídas por diferentes cargos municipales, por el baile general y por deudas variadas de menor enjundia. En total, el dinero ingresado por los impuestos ascendía a 833.280 sueldos, cantidad que supera al monto total de las imposiciones anotado inicialmente por los clavarios, de 801.900 sueldos, desajuste que sólo puede explicarse porque el impuesto de la carne era recolectado directamente por el municipio y los clavarios sólo anotaban provisionalmente una cantidad menor. Mientras, los ingresos procedentes de la deuda pública ascendían a los 973.478 sueldos (Arxiu Municipal de València - en adelante AMV-, Claveria de Censals, N-23; Claveria comuna, O-23; y Claveria del Quitament, W-4). La relación entre la tipología de ingresos era distinta una década antes. En 1437, las tres claverías ingresaron un total de 1.316.451 sueldos de los cuales 818.878 procedían de la recaudación fiscal, sólo 152.300 de la venta de nuevos censales y 243.755 sueldos aportados por el baile general para 
municipal ordinario era sobrevenido y las arcas municipales necesitaban continuamente de la emisión de deuda. Por tanto, a la vez que el municipio amortizaba deuda antigua iba generando nueva, en general a mayor ritmo. Dado que el endeudamiento del municipio a través de la venta de censales quedaba indisolublemente ligado a los mecanismos de reproducción económica del patriciado, comprador principal de aquellos ${ }^{7}$, la única vía posible de saneamiento de las finanzas municipales debía pasar por la mayor eficiencia en la recaudación de la tributación indirecta.

\section{Las imposiciones}

Según las certificaciones realizadas por los escribanos del Consell en las partidas apuntadas por los clavarios en sus libros contables, el sistema fiscal indirecto había acabado sustentándose en diez imposiciones ${ }^{8}$. Seis de ellas gravaban el consumo alimentario: la compra de cereal por particulares en el Almudín, granero municipal (12 dineros por cahíz); la adquisición del grano por profesionales, hosteleros y panaderos ("lo capitol dels II sous VI diners que paguen de més ostalers e flaquers en lo pa que compren en l'Almudi de la ciutat"); la importación de pescado seco y salado (12 dineros); su exportación; el consumo de carne (4 dineros); y el de vino. Tres tributos recaían sobre la industria artesanal textil, consolidada en el siglo anterior: la venta de paños de lana al por menor; los tejidos de oro y de seda y la peletería; y la pañería y materias primas

afrontar el pago de las pensiones (AMV, Claveria de Censals, N-19; Claveria comuna, O-17; y Claveria del Quitament, W-3). Esta proporción parece mantenerse a mediados del XV. En el ejercicio fiscal de 1459 , las tres claverías ingresaron conjuntamente 1.124 .727 sueldos, de los cuales 731.000 procedían de los arrendamientos de impuestos, 142.350 de la venta de nueva deuda pública, 67.679 aportados por el baile general y 183.698 sueldos de otros conceptos (AMV, Claveria de Censals, N-30; Claveria comuna, O-31; y Claveria del Quitament, W-6). Diez años más tarde, en 1469, se reproduce la situación de 1446: el municipio incrementaba sus activos, no tanto a través del aumento de la recaudación fiscal, que era más o menos estable, 875.600 sueldos, sino de la venta de mayor deuda pública (695.350 sueldos), aunque no se alcanzaron los niveles de 1446, y del incremento de los ingresos derivados de una variada gama de procedencias. En total, las tres claverías sumaron 2.030.240 sueldos, casi el doble que el de un año normal (AMV, Claveria de Censals, N-34; Claveria comuna, O-37; y Claveria del Quitament, W-7).

7 Juan Vicente García Marsilla, "Avalando al rey. Préstamos a la Corona y finanzas municipales en la Valencia del siglo XV", Fiscalidad de Estado y fiscalidad municipal en los reinos hispánicos medievales, Casa de Velázquez, Madrid, 2006, p. 387.

8 La certificación que los escribanos de la Sala hacían en los márgenes de las partidas anotadas por los clavarios, tanto en la época de Antoni Pasqual como en la de Jaume Beneït, para verificar el precio de los arrendamientos recaudados por los contables solía tener una fórmula del estilo: "És cert que·ls capítols de les imposicions de la ciutat de València són deu" (AMV, Claveria comuna, O-11). Sin embargo, no era así. Desde bien temprano -década de 1420- se mencionan otros impuestos indirectos, menos gravosos, que afectaban a otras magistraturas urbanas y no estaban fiscalizados por los clavarios. Por ejemplo, la col lecta o imposició dels Avenguts, impuesto que gravaba el consumo de pan extramuros de la ciudad ("capitulum imposicionis panis dictum dels Avenguts extra menia civitatis eiusdem"), recaudación destinada a la financiación de la Obra de murs $i$ valls, a cuyos oficiales se delegaba la misión de gestionar su arrendamiento (AMV, Protocols Notarials, 24-5, J. Beneit). Sí que fueron ingresados por los clavarios otros impuestos indirectos que irían desapareciendo con el tiempo como el que se instauró coyunturalmente para financiar la Font del Grau. 
llegadas de otros lugares del reino9. En último lugar, la imposición de la mercaderia repercutía sobre una variada gama de artículos producidos por el resto de artesanías locales $(6 \text { dineros })^{10}$. En conjunto, la recaudación fiscal se sustentaba sobre los impuestos de la mercancía, de la carne y, en menor medida, del corte de paño de lana y del vino, que podían sumar conjuntamente las dos terceras partes del ingreso anual.

La eficiencia del sistema tributario indirecto residía principalmente en el mecanismo de recaudación. Los magistrados urbanos tenían dos opciones: la colecta directa por el municipio, a través de regentes y colectores de cada impuesto; y el arrendamiento de los impuestos a particulares a través de subasta pública, mecanismo probado en la centuria anterior y que prevaleció a lo largo del siglo $\mathrm{XV}^{11}$. Cada año, hacia el mes de mayo, en la época de cambio de la Juraderia, los magistrados urbanos, junto con los administradores de los impuestos, otro cargo municipal, y escribanos acudían a la lonja de la ciudad, auxiliados por corredores, para dirigir la puja por la compra de los arrendamientos.

En la actualidad, la historiografía no se ha definido claramente sobre la eficacia del arrendamiento de la recaudación de los impuestos indirectos. "El único medio de percibir eficazmente los impuestos indirectos sobre el consumo...es arrendarlos" ${ }^{12}$. Quizás la preferencia por esta vía residía en la limitada capacidad financiera del municipio, por lo que el arrendamiento aseguraba una cantidad mínima de ingresos, independientemente del resultado del ejercicio fiscal; quizás en las restricciones impuestas por la organización administrativa y la falta de personal; o quizás simplemente porque facilitaba la elaboración anticipada de un presupuesto municipal provisional. Todas estas razones parecen poco documentadas y pueden ser contestadas en sentido contrario. Así, en la recaudación de los impuestos arancelarios bajo jurisdicción real se recurría a ambos procedimientos, la colecta directa por parte del baile general o el arrendamiento a terceros. En el primer caso, implicaba la contratación de recaudadores que temporalmente asumían, bajo dirección del oficial real, un trabajo para el cual la administración real no

\footnotetext{
9 En general se resume el título de este impuesto con la expresión más vaga de draps estranys, y en alguna ocasión hace relación a la pañería de fuera de la ciudad pero del propio reino: "entrada dels draps cruus e filaces de seu e sagí e de cuyram de passatge" (AMV, Claveria comuna, O-18).

10 Algunos de ellos eran aceite, curtidos, artículos de esparto, alfarería, corambre, productos de madera, peletería, quincallería, lana y paño de lino. Este impuesto gravó hasta 1423 con cuatro dineros su consumo, si bien en algunos ejercicios fiscales se aplicaba un gravamen extraordinario y coyuntural, durante unos meses, de dos dineros más. A partir de 1424, en el contexto de una tendencia a un crecimiento lento del precio de los arrendamientos, el tipo de gravamen se elevó a los seis dineros. Siendo el tributo más importante de los diez que financiaban las tres claverías de la ciudad, este incremento del $50 \%$ repercutió sobre la evolución global de los precios de los arrendamientos. Si en 1411, el montante total ascendió a 785.992 sueldos (Rafael NARBona VizCAíno, "Cultura política..., p. 196), en 1420 se mantenía en 869.100 y en 1424 sumaban 914.600, cuando el impuesto de la mercaderia había pasado a arrendarse por un precio de 200 a 300.000 sueldos (AMV, Claveria de Censals, N-11 (1420) y N-12 (1424), y Claveria comuna, O-9 (1424)).

11 Juan Vicente García Marsilla, "Las empresas del fisco. Arrendamiento y gestión privada de los impuestos en el reino medieval de Valencia (siglos XIV y XV)", La fiscalità nell'economia europea. Secc. XIII-XVIII, Firenze University Press, Florencia, 2008, pp. 851-861.

12 Jean FAVIER, Finance et fiscalité au bas Moyen Âge, Armand Colin, París, 1971, p. 226.
} 
disponía de personal. La desventaja de este esfuerzo administrativo suplementario se compensaba con la mayor posibilidad de una explotación exhaustiva de la recaudación. Por el contrario, el arrendamiento ahorraba trabajo administrativo pero implicaba limitar la recaudación al montante inicial acordado, independientemente de las condiciones del mercado ${ }^{13}$.

Si entendemos la eficacia como una consecuencia del grado de preparación intelectual o profesional del recaudador, da lo mismo que los impuestos fueran colectados directamente por la ciudad o arrendados, porque los funcionarios municipales (clavarios, administradores, etc.) y los arrendatarios eran las mismas personas o pertenecían al mismo grupo profesional. Por otra parte, es difícilmente comprensible cómo, si el municipio carecía de la infraestructura organizativa mínima, un particular, que además arrendaba el impuesto sólo por un año o por lo menos sin la seguridad de conseguir el arrendamiento al siguiente año, podía gestionar la colaboración asalariada de un grupo de hombres destinado a la recaudación. Más incomprensible es que, si para cobrar un impuesto era necesario contar con el apoyo de una fuerza coercitiva, único medio para obligar a pagar a morosos y defraudadores y vigilar el mercado, los arrendatarios contasen con el necesario margen de acción. Según las ordenanzas del Quitament de 1434, el arrendatario del impuesto recibía un bastón que simbolizaba la autoridad recibida del municipio para cumplir su actividad; pese a ello, la capacidad coercitiva para apresar a los deudores quedaba en manos de los administradores de los impuestos ${ }^{14}$ (si bien estos cargos eran ocupados por aquellos mismos comerciantes).

Tampoco parece plausible una explicación financiera, ya que cuando por motivos de una guerra o de una epidemia se producían fuertes pérdidas en la recaudación de un impuesto, éstas no recaían sobre el cálculo de riesgo de la empresa arrendataria sino, al eximírsele del pago de una parte del precio del arrendamiento, sobre las arcas municipales ${ }^{15}$. Los perjuicios padecidos por varios arrendamientos municipales, en 1435, llevó a sus titulares a reclamar una reducción de parte del precio a los jurados. Pere Bou,

\footnotetext{
13 Winfried Küchler, Les finances de la Corona d'Aragó al segle XV (regnats d'Alfons V i Joan II), Ed. Alfons el Magnànim, València, 1997, p. 50.

14 Salvador CarReres Zacarés, Libre de memòries..., vol. I, pp. 541 y 542.

15 Así, por ejemplo, los arrendatarios de los impuestos de 1401 se quejaron de la merma habida en los arrendamientos provocada por las mortandades y la conflictiva vida política de la ciudad, solicitando al Consell una rebaja de parte del precio. Éste delegó en los jurados el procedimiento de información sobre los posibles daños tenidos en cada uno de los capítulos impositivos. Las autoridades, acogiéndose a una cláusula incluida en los capítulos de los arrendamientos de los impuestos según la cual "no putxa o deia ésser feta gràcia o relexació d'alcuna part del preu", denegaron hacer cualquier descuento en el precio. A pesar de la decisión, resolvieron que aquellos fuesen comportats o supportats mediante la emisión de deuda pública por valor de 8.500 sueldos, ya que respaldar a los arrendatarios, concederles gràcia e support, era "congruent fer per ço que les imposicions e preus d'aquelles no reeben detriment o disminució", lo que implicaría que la ciudad tuviese "fretura de peccúnia a obs de complir als dits càrrechs e necessitats", es decir, la formación de armadas que defendiesen la costa y el abastecimiento de la ciudad que evitase las penurias alimentarias. Por tanto, argumentando que los intereses privados redundaban en el beneficio público, se pretendía en última instancia salvaguardar éste (1401, diciembre 3; 1402, enero 26. AMV, Manuals de Consells, A-22, f. 148).
} 
arrendatario del impuesto de las carnes, confirmó tener pérdidas y consiguió finalmente del Consell la exención del pago de dos meses del arrendamiento. También Antoni Gil logró el perdón de parte del precio adeudado por el arrendamiento del impuesto del trigo vendido en el Almudín. En esta coyuntura negativa, los arrendatarios de las imposiciones de la anualidad siguiente obtuvieron, nada más les fueron adjudicados los arrendamientos en subasta, que el Consell les rebajase directamente el precio de cada uno de los capítulos ${ }^{16}$. De la misma manera, los libros de contabilidad municipal recogen menciones a la rebaja de los precios de los arrendamientos en ese y otros años ${ }^{17}$. Esta práctica debió de ser relativamente frecuente ${ }^{18}$.

En último lugar, la relación entre arrendamiento y presupuesto municipal tampoco parece evidente por cuanto, a pesar de arrendarse anualmente, las imposiciones no eran pagadas en su totalidad al principio, sino que se aplazaba a lo largo del año siguiendo el ritmo marcado por la recaudación, produciéndose en algunos casos concesiones graciosas que prolongaban el reembolso más allá incluso de los plazos pactados inicialmente ${ }^{19}$. También la contabilidad municipal recoge con bastante frecuencia el aplazamiento de mensualidades de arrendamientos de años anteriores a los de la clavería en curso ${ }^{20}$.

\footnotetext{
16 Respectivamente, 1436, abril 13 (Ibid., A-31, f. 77); mayo 26 (Ibid., f. 94); y mayo 22 (Ibid., ff. 84-85 y 87).
}

17 El caso de 1435 se halla recogido en AMV, Claveria comuna, O-17. Por ejemplo, la imposición de la mercancía recibió en conjunto un descuento de 359 libras y 6 sueldos. También los protocolos de los notarios municipales se hacen eco de estas reducciones de los precios. Por ejemplo, en 1452 una sociedad arrendataria de cuatro impuestos obtuvo la rebaja de 31.000 sueldos, una quinta parte del precio del arrendamiento realizado en 1450, año de epidemia (1452, mayo 26. AMV, Protocols Notarials, 24-5, Jaume Beneït).

18 En 1450, varios capítulos de los arrendamientos contenían una cláusula del estilo: “...ab condició emperò que si en los dits capitols o algú de aquells se seguia pèrdua alguna per causa de les mortalitats de que ha la gent se sospitava se devien seguir en la dita ciutat, en tal cas fossen tenguts fer smena o reffayçó als dits compradors a coneguda o determenació de dues persones notables, és a saber, del honorable en Manuel Suau, racional de la dita ciutat per part dels dits honorables jurats elet e nomenat, e de un altre per part dels dits compradors elegidor e nomenador...". Efectivamente, en agosto de 1451, meses después de haber terminado el periodo del arrendamiento, el racional confirmaba la compensación concedida: de los 150.000 sueldos del precio de los impuestos textiles y del vino, los arrendatarios sólo pagaron 119.180, es decir, se les aminoraba el $20 \%$ del precio inicial del arrendamiento (AMV, Claveria comuna, O-26).

19 Por ejemplo, en el mes de mayo de 1414, Pere Borràs, el clavario común en 1413, cobraba el precio de los primeros cinco meses del arrendamiento de 1413, es decir, al final del período fiscal (1414, mayo 24. Arxiu del Regne de València -en adelante, ARV-, Protocols, $\mathrm{n}^{\circ}$ 2.415, Vicent Saera). Es decir, el municipio no había ido recibiendo el dinero conforme se recaudaba, sino que lo había percibido al final del período de recaudación, es decir, casi un año más tarde de si lo hubiera recolectado el propio municipio. En febrero de 1415, el mercader Gabriel Rigolf, por entonces clavario de la ciudad, cobraba a la vez a Joan Mainés siete meses (de junio a diciembre) de la imposición de entrada de paños extranjeros (1415, febrero 15. Ibid., $\mathrm{n}^{\circ}$ 2.416). Y unos años más tarde, el mismo Mainés pagaba todo el precio del arrendamiento de un impuesto municipal al final del período de recaudación (1418, enero 14. Ibid., $\mathrm{n}^{\mathrm{o}} 2.419$ ).

20 Es el caso concreto de la clavería del Quitament, parte de cuyos ingresos procedían de la liquidación de las deudas contraídas por los cargos municipales y otros morosos. Así, durante la clavería de Galceran d'Eixarch, durante los ejercicios presupuestarios de 1438 y 1440, anotó 17 libras y media a Gil Pérez, del arrendamiento del impuesto del Almudín de 1429; 122 libras a mosén Joan d'Eixarch por el mismo impuesto de 1435; 203 libras y 8 sueldos de los capítulos de la quincallería y del impuesto de hosteleros de 1435; 
Por tanto, si el arrendamiento de los impuestos tuviera como objetivo descargar a la institución pública del peso de la recaudación y asegurar la regularidad o el adelantamiento de los fondos, no parece que, con el evidente trato de favor con que contaban algunos arrendatarios, aquellos objetivos se pudiesen alcanzar. Difícilmente, bajo estas condiciones, podía ser posible o creíble la confección de un presupuesto financiero ordinario, ni útiles los arrendamientos de las tasas indirectas.

Si el arrendamiento no era fijado en función de la estimación real de los ingresos previsibles procedentes de la actividad económica gravada, sino a partir de otros criterios políticos y financieros, que llevaba a fijar solo mínimos aceptables, la transferencia de rentas se hacía en beneficio de las empresas privadas y en perjuicio de las arcas públicas. En este sentido, las autoridades municipales no son muy explícitas sobre las razones que condicionaban la toma de decisiones, o sobre la preferencia sobre uno de los dos procedimientos, colecta o arrendamiento. Un ejemplo fue el arrendamiento de la imposición de la carne. A partir de 1435, dejó de arrendarse, en principio porque no se encontró comprador que cubriera el precio razonable considerado por los magistrados: "lo qual capitol... no fon venut com no si trobàs preu raonable o covinent e per tant fon cullit per la dita ciutat e comanat a...". Pocos años más tarde, la argumentación había cambiado. Era provechoso para la ciudad su colecta directa a través de recaudadores: "lo dit capitol no fon venut ans de ordinació dels honorables jurats...fon cullit com fos vist a aquells ésser pus profitós...com experiència en lo temps passat ho haia mostrat". Esta imposición no volvería a ser incluida en el procedimiento público de subasta hasta 1448, es decir, trece años más tarde, y durante aquel largo período el colector fue casi siempre la misma persona, Pere Maiques, un mercader con intereses en el sector ${ }^{21}$. En cualquier caso, puede significar que, en primera instancia, el procedimiento de la subasta de los arrendamientos no atraía suficientes capitales y, en segundo lugar, que la ciudad recaudaba más a través de la colecta directa.

De hecho, las ápocas redactadas por el escribano Jaume Beneït relativas a la fiscalización del dinero y las cuentas entregados por Pere Maiques y Joan Canemàs revelan que la recaudación derivada de la colecta municipal era mayor que la cantidad anotada por los clavarios en concepto de colecta del impuesto, lo cual evidencia que los presupuestos declarados por los clavarios eran estimativos. El 31 de mayo de 1441,

18 libras a Joan Alegre del impuesto de la mercadería de 1426; 407 libras y media de Pere Igualada del impuesto del Almudín de 1438; 140 libras de los administradores de la carne de 1436; casi 1.569 libras de Pere Bou del impuesto de la carne de 1435; y 254 libras y media de los herederos de mosén Guerau Bou del capítulo del corte de paño de una fecha indeterminada. Es decir, a lo largo de dos años y medio, este clavario recibió más de 54.000 sueldos de retrasos en el pago de los plazos de los arrendamientos municipales (AMV, Claveria del Quitament, W-4). También entre las ápocas que registraba el escribano de la Sala, hay algunas que delatan los retrasos en el pago de los plazos. En su protocolo de 1453, Jaume Beneït anotaba 216 libras y 14 sueldos de los compradores de la imposición de la carne de 1449; 4.971 libras de una sociedad arrendataria de cuatro imposiciones de ese mismo año; más 1.350 libras de los mismos arrendatarios del primer impuesto citado (1453, marzo 10. AMV, Protocols Notarials, 24-5).

21 Citas de los años 1436 y 1437 (AMV, Claveria de Censals, N-18 y N-19); y 1448, mayo 24 (AMV, Protocols Notarials, 24-5). 
las autoridades reconocían que ambos habían ingresado 765.723 sueldos durante tres ejercicios fiscales, de 1436 a 1438. En junio de 1442, repetían un acta similar para los años 1439 a 1441 por un valor total de 728.559 sueldos. Y en enero de 1444, se redactaba un acta por valor de 251.156 sueldos para el año 1442. Eso implica que la media del ingreso del impuesto de la carne durante el primer trienio fue de 255.241, de 242.853 para el segundo, y de 251.156 sueldos para el ejercicio fiscal de $1442^{22}$. La cuestión estriba en que los clavarios consignaban en sus cuentas, al menos desde 1440, una cantidad menor, 200.000 sueldos, que debían percibir de los colectores municipales, indiferentemente de cuál fuera la recaudación real. Por tanto, la presión fiscal de un año no repercutía completamente sobre el presupuesto anual y, por tanto, éste no refleja de manera fidedigna aquélla. A partir de 1448, la imposición de la carne volvió a ser arrendada. Empezó con un precio elevado en ese año, 280.000 sueldos; sin embargo, a lo largo de la década de 1450 se estabilizó en los 250.000 sueldos, con mínimos de 238.00, es decir, que se arrendaba a precios similares de las cantidades recaudadas por el municipio, sólo que la contabilidad municipal dificulta la comparación. De ello puede inferirse que el intervencionismo del municipio suponía una presión sobre los arrendatarios, que se veían obligados a incrementar el precio para quedarse el arrendamiento, y que, por tanto, tampoco en el seno de la oligarquía municipal había un consenso unánime sobre la preferencia por uno de los dos procedimientos recaudatorios, colecta y arrendamiento.

Otros argumentos pueden facilitar la comprensión de las razones del arrendamiento de los impuestos indirectos. La frecuencia con que los arrendatarios conseguían hacerse con la contrata mediante la utilización de testaferros, plantea la duda de si no pretendían camuflar, por lo menos hacer que no fuera evidente, la identidad de los verdaderos titulares de los arrendamientos. Así, tanto por el procedimiento como por el lugar donde se desarrollaba la subasta, el sistema de arrendamiento de impuestos municipales quedaba restringido a una minoría social: el grupo de empresarios que diariamente se movía en esos ambientes selectos de la lonja mercantil de la ciudad. Todo ello tiene una consecuencia inmediata: los precios de los arrendamientos permanecían en niveles bajos, en perjuicio del interés público y en provecho de los contratistas, guardando un paralelismo lejano con la dinámica económica del mercado y la internacionalización de la economía urbana ${ }^{23}$. En este sentido, alguna documentación, siempre escasa, hace referencia a la estrategia de los licitadores en las subastas para "entre sí aunar per abatre los preus" de los arrendamientos, en ese caso referido a las generalidades del reino ${ }^{24}$. Por tanto, aquella débil atracción de capitales hacia el mercado de arrendamiento de impuesto podría estar relacionada con el acaparamiento del mismo por una reducida élite financiera.

22 1441, mayo 31 y 1442 junio 28 (AMV, Protocols Notarials, 24-3, J. Beneï); 1444, enero 4 (Ibid., 24-4).

23 Jacques Rossiaud, "Crises et consolidations, 1330-1530", Histoire de la France urbaine, Georges Duby (dir.), Ed. Seuil, París, 1980, p. 513.

24 María Rosa MuÑoz Pomer, Orígenes de la Generalidad Valenciana, Generalitat Valenciana, València, 1987, p. 495. 


\section{EI arrendamiento}

El análisis de la evolución de los arrendamientos entre 1425 y 1460 demuestra una tendencia a la baja de los precios durante aquel periodo, tendencia que contrasta con la evolución económica del mercado valenciano a lo largo de aquellas décadas, considerada por la historiografía como fase de crecimiento.

FigurA 1

\section{Precio en sueldos de los arrendamientos anuales de los impuestos municipales $(1425-1460)^{25}$}

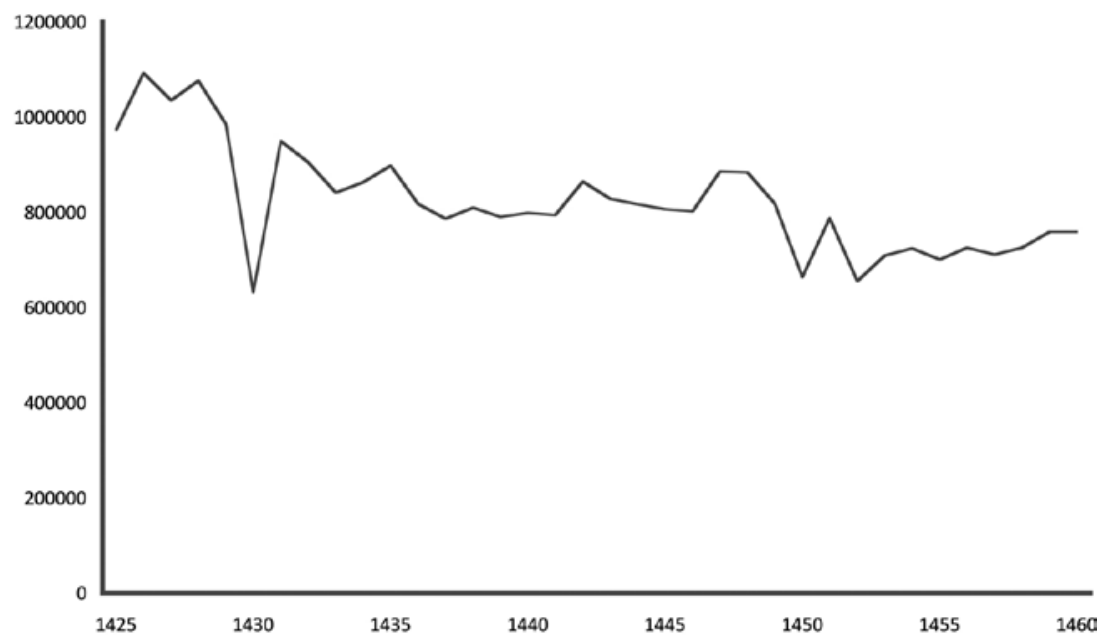

La misma documentación institucional informa sobre las coyunturas difíciles. La brusca caída de los arrendamientos en 1430 estuvo condicionada por el conflicto militar con Castilla, que obligó al municipio a asumir la recaudación. También, durante los primeros cuatro o cinco meses del año fiscal de 1440, la ciudad se encargó directamente de

25 El gráfico ha sido confeccionado con la siguiente documentación: Claveria comuna, entre las signaturas O-11 y O-30, distribuidos desigualmente entre los años 1428 y 1457; Claveria de Censals, entre la N-13 y la N-31, de 1434 a 1458; Claveria del Quitament, los registros W-3 y W-4, que abarcan los años 1434 a 1447; y los protocolos de los escribanos municipales 24-1 a 24-6, que conservan los pocos supervivientes de la actividad de Antoni Pasqual y Jaume Beneït, notarios de la Sala del Consell entre 1425 y 1471. De todo el período, sólo hay un pequeño grupo de años (7) en que no se ha podido conseguir la información completa de los precios de todos los arrendamientos. Para evitar la distorsión de la tendencia, en esos casos el dato se ha obtenido mediante el promedio de los precios del mismo arrendamiento en los años próximos. 
la colecta, quizás a consecuencia de los efectos de la epidemia del año anterior. Solo el impuesto del vino fue arrendado en subasta con el comienzo de la juradería. Entre finales de septiembre y principios de noviembre, los magistrados volvieron a subastar las imposiciones. Sin embargo, durante la mayor parte de la década de 1430 los impuestos fueron arrendados, lo que no frenó el paulatino descenso de la recaudación, con otro mínimo en 1437. La recaudación había descendido de más de un millón de sueldos entre 1426 y 1428 a cerca de 786.385 en 1437. En este año, se arrendaron los impuestos entre abril y mayo, excepto el del vino, que se retrasó hasta noviembre, y el de la carne, que ya no se había arrendado desde el año anterior porque no se consideraba razonable la oferta de los licitadores, según expresión del escribano ("com no si trobàs preu raonable o covinent") y que seguiría siendo recolectado por el municipio en los años siguientes porque se consideraba más rentable. El periodo siguiente está marcado por cierta recuperación de los precios, hasta alcanzar el máximo de los 885.000 sueldos de 1447, año a partir del cual se produce otra caída, llegando a los mínimos de 1450 y 1452, algo más de 650.000 sueldos $^{26}$. En 1450, año en que la ciudad fue asolada por una epidemia, la imposición de la mercancía, la más cuantiosa de las finanzas del municipio, fue recaudada por el municipio hasta noviembre, cuando volvió a ser alquilada. En 1452, la imposición de la mercaderia fue desgajada: las filloles fueron arrendadas en junio; la parte central del capítulo recaudado directamente por el municipio a través de regentes. Este impuesto, el de la mercaderia, tampoco sería arrendado en los años $1455-1458$, y su recaudación, encomendada a particulares, se combinaba con la venta de algunas de sus filloles. A partir de entonces, los precios subieron nuevamente de manera lenta, con un breve retroceso en 1460, ante la amenaza de nuevas epidemias y conflictos con Castilla ${ }^{27}$.

Es obvio que los descensos en la recaudación coinciden con ocasiones en que el municipio no consigue arrendar alguno de los impuestos debido a coyunturas difíciles. Sin embargo, la incidencia de acontecimientos bélicos o epidémicos no parece determinar plenamente la evolución del sistema fiscal. El Dietari del Capellà cita, para esta época, cuatro brotes epidémicos más graves $(1428,1439,1450$ y 1458$)$ y una crisis de abastecimiento alimentario $(1435 \text {, la tercera fam })^{28}$. Según la documentación, la repercusión de factores extraeconómicos se limita sin embargo sólo a los años de la guerra con Castilla, en concreto 1430, y a la epidemia de 1450, que quizás explica el

\footnotetext{
26 Si bien tanto en 1450 (664.000 s.) como en 1452 (654.994 s.) la cifra total de los ingresos fiscales del municipio debería ser algo mayor, por cuanto éste se encargó de la recaudación directa del impuesto de la mercaderia, gestión cuyos resultados financieros no aparecen bien reflejados en la documentación contable oficial. La corrección de esas cifras supondría una pendiente menos pronunciada, más próxima a los mínimos de 1453 (709.000 s.) y 1455 (701.000 s.).

27 1460, mayo 19 (AMV, Protocols Notarials, 24-6, J. Beneït).

28 Josep Sanchis Sivera, Dietari del Capellà d'Anfós el Magnànim, Ajuntament, València, 2001. Por ejemplo, la documentación institucional recoge que en 1439 había mortandats en la ciudad, lo que debería afectar a la recaudación impositiva; sin embargo, la recaudación no experimenta cambios substanciales en comparación con los otros años fiscales cercanos (1439, mayo 12-30; AMV, Protocols Notarials, 24-3, J. Beneit). Algo similar se puede argumentar con la epidemia de 1458, año fiscal en que la recaudación era superior a las de las anualidades del entorno, si bien podría explicar el descenso de 1459 .
} 
retraso del arrendamiento de la mercaderia hasta noviembre de ese año. Más allá de estas repercusiones coyunturales es apreciable una tendencia a la baja de los precios de los arrendamientos a lo largo de esas décadas. En una época en que se considera que Valencia se vio beneficiada por un crecimiento del volumen de los intercambios y un aumento de la población.

Para conjurar la posible falta de arrendatarios que asumieran las exigencias financieras mínimas del municipio, los jurados ofrecían primas o adehalas (eixaucs) a aquellos licitadores que hicieran subir las pujas. Este procedimiento puede servir de indicio para rastrear los años considerados por las propias autoridades municipales como problemáticos para la venta de los arrendamientos. Sin embargo, en el periodo analizado solo se han encontrado referencias a estas gratificaciones al principio del periodo analizado, en 1427, 1429, 1431 y 1433. Es decir, a pesar de la tendencia a la baja y estabilización final de los precios, dejó de considerarse oportuno ofrecer primas, lo que puede estimarse como indicio de que esa tendencia no era juzgada como grave por las autoridades municipales ${ }^{29}$.

Por tanto, o bien la política fiscal no guardaba correlación con la dinámica del mercado interior, según se considera, en fase de crecimiento, o bien el sistema, con sus procedimientos, era deficitario y poco adaptable a la coyuntura económica. En concreto, la documentación induce a pensar que la demanda, conformada por un grupo más o menos reducido de hombres de negocios, controlaba el mercado. De hecho, las propias autoridades municipales se refieren a ellos como "los mercaderes que solían arrendar los impuestos", lo que invita a pensar en un sistema más o menos restringido. Por otra parte, aunque la documentación es escueta en este tipo de informaciones, esos comerciantes debían presionar a las autoridades municipales para conseguir los arrendamientos en las condiciones más ventajosas ${ }^{30}$.

\footnotetext{
29 Aunque estas gratificaciones necesitarían de una investigación más detallada. Por ejemplo, en el arrendamiento de la imposición de la mercaderia de 1433, ganó la subasta Bernat Punyet, que la compró por cuenta del mercader Joan Alegre. Se alcanzó el precio de 250.000 sueldos y recibió una prima de 2.000 sueldos por haber ofrecido los últimos 5.000. Sin embargo, ese mercader, Alegre, venía arrendando el capítulo, al menos, desde 1431; continuó arrendándolo durante esa década y, como se verá, formó parte de la sociedad que lo acaparó durante la de 1440. Es cierto que aquel año fue uno de los peores arrendamientos, pero al menos recibió los 2.000 sueldos, porque el arrendamiento de 1436 se vendió por 245.000 y la ciudad no ofreció prima alguna. En 1431, Joan Alegre había arrendado también la imposición de la mercancía a través de Bernat Punyet: se alcanzaron los 280.000 sueldos y recibió 4.000 de eixauc. Así, en última instancia, la prima se convertía en un mecanismo que, al mismo tiempo que aseguraba la participación de las sociedades que monopolizaban el mercado, abarataba el coste para los arrendatarios que solían acaparar las subastas. 30 En 1417, el mercader Joan Mercer nombraba procurador a Rosell de Bellpuig para que comunicase a los jurados de la ciudad que arrendaría los impuestos de la ciudad siempre y cuando ellos asegurasen el control de movimientos de las compañías italianas: "que los honorables jurats e Consell...ordenaran e provehiran...que los forasters de la dita ciutat no puxen comprar algunes mercaderies del regne de València, si ja aquelles no compraven dins los murs de la dita ciutat e de ciutadans de aquella". Además, exigía que se rescindiese el avecindamiento a ciertos grupos que a través de su nueva ciudadanía escapaban al fisco municipal: "que...levaran totes les franquees que han de la dita ciutat los lombarts e pisans e jenoveses e tots altres forasters, los quals se són fets vehins e ciutadans de la dita ciutat". En caso de que el municipio
} 
A lo largo de esos años de tendencia a la baja de los precios de los arrendamientos, se observa otro fenómeno probablemente relacionado: la frecuencia con la que varios impuestos se arrendaban conjuntamente. Hasta finales de la década de 1430, pueden encontrarse casos de impuestos que, arrendados por separado, acaban recayendo en las mismas manos, generalmente las de los testaferros. Para entonces, comienza a observarse que algunos impuestos, por su similitud o afinidad, son arrendados conjuntamente. Por ejemplo, los dos impuestos, el de la importación y el de la exportación, del pescado seco y salado. También, el del corte de paños de oro y seda y el de la importación de paños foráneos. Sin embargo, a partir de la década de 1450, el arrendamiento conjunto de impuestos comienza a ser práctica habitual. En una fecha más temprana, en 1440, en un mismo día se arrendaron de golpe a una misma persona cinco capítulos (tall del drap de llana, los dos del Almudín y los dos del pescado). Mientras que los otros dos fueron agrupados por parejas: los otros dos de paños y el de la mercaderia junto con el del vino ${ }^{31}$. Al año siguiente, sucedería algo similar, inaugurando una práctica que con el tiempo se acentuaría cada vez más. En 1457, los arrendamientos se habían agrupado en dos de cuatro capítulos cada uno y, por separado, el de las carnes y el de la mercaderia, que se fraccionó en sus filloles ${ }^{32}$. A partir de 1460, la oferta se concentró aún más. Los impuestos municipales fueron arrendados en dos grupos: una venta de cinco arrendamientos (el de las carnes, los tres que afectaban a los textiles y el vino) y otra de otros cinco (la mercaderia, los dos del Almudín y los dos del pescado) ${ }^{33}$. La variación en el procedimiento de la subasta, mediante el cual se concede un mayor número de arrendamientos a sociedades financieras que monopolizaban la demanda, puede ser una respuesta al descenso pronunciado de los precios de los arrendamientos, pero sin duda tienen el efecto nocivo de acabar con cualquier competitividad dentro del mercado. Al mismo tiempo, también puede indicar que la demanda del mercado era cada vez más reducida, controlada por un grupo financiero elitista.

\section{Primeras décadas: prerrogativa de mercaderes}

A pesar de que el procedimiento contemplase la adjudicación de los arrendamientos mediante subasta pública, la documentación demuestra una práctica consolidada: la participación de testaferros que pujaban para conseguir los arrendamientos por cuenta de los socios principales. También la misma documentación municipal demuestra que los magistrados conocían la intervención de estos personajes, lo cual no es extraño si se tiene en cuenta que los arrendatarios solían ocupar puestos en las magistraturas

atendiese a su demanda, Mercer aseguraría varios impuestos durante cinco años por valor de 25.000 libras más que el precio de venta de ese año (1417, marzo 19. ARV, Protocols, $\left.\mathrm{n}^{\circ} 2.418\right)$.

31 AMV, Claveria comuna, O-20.

32 AMV, Claveria comuna, O-30.

33 AMV, Protocols Notarials, 24-6, J. Beneït. En principio, esa concentración no se mantiene con la misma intensidad en los dos años siguientes. 
urbanas. En los contratos redactados por Antoni Pasqual en $1425^{34}$, se escrituraba el acta de la venta del arrendamiento cerradas por el notario Joan Aguilar ("Com en Berenguer Verdú hagués tret e comprat lo capitol de la mercaderia dels honorables jurats de la ciutat de València...") al tiempo que se citaba el reconocimiento del verdadero titular del arrendamiento ("E lo dit en Berenguer Verdú digués que lo dit capitol havia treyt per ops del honrat en Pere Giner, mercader qui alli era de present e no pas per a ops de si matex..."), recogiéndose el interrogatorio realizado por los jurados a éste (“...interroga lo dit en Pere Giner si era ver que lo dit en Verdú hagués comprat lo dit capitol de la mercaderia per ops d'ell") y la admisión de la titularidad ("E lo dit honrat en Pere Giner dix que hoc que ver era que lo dit en Verdú havia treyt lo dit capitol per ops d'ell...e que ell era lo comprador..."), por lo que se le hacía jurar el cumplimiento del capítulo del arrendamiento. Este procedimiento se repetiría en otros contratos de los arrendamientos de ese mismo año y de los años siguientes, simplificándose las clausulas aunque manteniéndose la referencia de la existencia del testaferro que había pujado y su principal mediante la locución $a$ ops $d e^{35}$. En la mayor parte de los años, aun existiendo testaferros, no había voluntad de explicitar las identidades de los verdaderos compradores.

Una vez tomada posesión del arrendamiento, el comerciante que había obtenido la subasta ponía en marcha la organización del nuevo negocio. Por un lado, podía nombrar procuradores para encargarles la recolecta o vigilancia del negocio ${ }^{36}$. Además, en aquellas imposiciones que lo permitían, el riesgo y la gestión podía fragmentarse a través del subarrendamiento, sistema que se aplicaba a la recaudación de las generalidades mediante la organización de la recaudación por quarters. En concreto, la imposición de la mercancía, fragmentada en una variedad tipológica de artículos, se desglosaba en filloles, hijuelas, las cuales eran vendidas por separado a diferentes subarrendatarios.

Los elevados riesgos propios de estos negocios provocaron que bien pronto se aplicaran nuevas fórmulas empresariales a la gestión de los arrendamientos de impuestos. En concreto, se trasladó el mecanismo de la división de la propiedad en participaciones, aplicado hasta entonces en las sociedades armadoras de naves. Así, el titular del arrendamiento reconocía a través de contrato notarial que otros hombres de negocios poseían setzenes o desetenes en la propiedad del arrendamiento.

Aunque de manera episódica, con información para pocos años seguidos, pueden encontrarse ejemplos más tempranos. Francesc Siurana, un conocido cambista de la época, ya colaboraba desde 1414 en una sociedad junto a Joan Mainés, Joan Ripoll, Joan Alegre y

34 Ibid., 24-1 (el arrendamiento del impuesto de la mercaderia es de fecha 1425, junio 13).

35 Por ejemplo, en el arrendamiento de la mercancía de 1439 adjudicado a Jaume Bramon se decía que había actuado ad oppus de Joan Alegre, principal copartícipe (mayo 20. Ibid., 24-3, J. Beneït).

36 Lluís Conca, avalista, arrendatario principal y clavario del arrendamiento del impuesto del vino de 1446, designaba como procurador al mercader Miquel Andreu para que recaudara tasas que le debían aún de quedar por cobrar (1447, octubre 25. Archivo de Protocolos del Colegio del Corpus Christi de Valencia -en adelante, APCCV-, protocolo no 25.974, Pere Castellar). 
Jofre de Meya en el arrendamiento de impuestos municipales ${ }^{37}$. Dos años después, Daniel Barceló, Francesc Siurana, Joan Navarro, Joan Bayona, Jofre de Meya, Joan Mainés, el hermano Francesc Barceló, Joan Ripoll, todos ellos mercaderes, se repartían la imposición de la carne comprada por 360.000 sueldos, un precio elevadísimo si se compara con el de unas décadas más tarde, a través de un testaferro, Nicolau Salvat, un corredor ${ }^{38}$.

En febrero de 1417, Joan Ripoll adquiría el arrendamiento del impuesto de los paños de oro y seda y de la peletería durante un año y cinco meses por valor de 33.000 sueldos. Poco después reconocía a través de un contrato privado que dicho arrendamiento lo había realizado por cuenta de Joan Navarro. Ese mismo día, este último comerciante confirmaba la participación de una serie de socios, lista que meses después se vería ampliada. En un primer momento, eran copropietarios Joan Ripoll, Pere Borràs, Joan Alegre, Galceran Martí y Joan Guillem. Aun así, Navarro acaparaba prácticamente la mitad del arrendamiento, por lo que con posterioridad se deshacía de sus participaciones al vendérselas a otro grupo de mercaderes: Daniel Barceló, Joan Bayona, Jofre de Meya y Joan Mainés. Ese mismo día de abril, Mainés, como arrendatario del impuesto del trigo, pagado por panaderos, horneros y hosteleros, valorado en 60.000 sueldos, admitía como socios al mismo grupo de inversores: los mercaderes Joan Bayona, Jofre de Meya, Joan Navarro, Daniel y Francesc Barceló, Pere Borràs y Joan Ripoll ${ }^{39}$.

En 1418, Joan Mainés había comprado la imposición de los panaderos y poseía una setzena, junto a Joan Alegre, de la de la mercancía. Francesc d'Artés, un cambista, era el principal socio del impuesto del Almudín ${ }^{40}$. Sin embargo, en esta época la competencia entre arrendatarios debía de ser mayor: en 1419, la imposición de la carne estaba en manos de una sociedad distinta, donde los miembros de la familia Bou poseían una parte mayoritaria de las participaciones ${ }^{41}$.

En 1420, Francesc Çafont, un torcedor de paños, arrendaba el impuesto del corte de paño para posteriormente reconocer su propiedad a la sociedad formada por Joan Alegre, Francesc Siurana y Francesc Martí, de la que era clavario este último. En un primer momento, los tres socios habían distribuido cuatro setzenes y media entre un número elevado de maestros artesanos, pañeros, pelaires y sastres. A su vez, Francesc Martí, a través de la cesión de algunas de sus participaciones, integraba en la sociedad a Joan Bou y Pere Bou. Lo mismo que Joan Alegre hacía con el mercader de origen lombardo Nicolau Montell. Un corredor, Bertomeu Vilar, había comprado el impuesto del vino, valorado en 62.100 sueldos, por cuenta de Antoni Bisbar y Guillem Conques. Estos dos ciudadanos admitían que Pere Borràs, Francesc Siurana, Joan Alegre y Francesc Martí participaban en el arriendo con una setzena de propiedad cada uno. Martí transferiría después media setzena a Joan Bou; y Alegre, a Montell. En agosto de ese año, Ferran Guillem, un ciudadano que había comprado a la ciudad el impuesto de la carne por 268.500

7 1414, junio 13 (ARV, Protocols, $n^{\circ} 2.415$, V. Saera).

38 1416, enero 8 (2) (Ibid., $\left.\mathrm{n}^{\mathrm{o}} 2.417\right)$.

39 1417, febrero 20 (2), abril 14 y 22 (2) (Ibid., $\mathrm{n}^{\mathrm{o}} 2.418$ ).

40 1418, mayo 21 (2) y diciembre 1 (Ibid., n ${ }^{\circ} 2.419$ ).

${ }_{41} 1419$, septiembre 22 y octubre 19 (Ibid., $\mathrm{n}^{\circ} 2.420$ ). 
sueldos, reconocía que lo había adquirido por cuenta de Alegre, Siurana, Borràs y Martí, aceptando como clavario del arrendamiento a Francesc Siurana. En esa misma subasta, Borràs había obtenido la imposición del trigo, valorada ese año en 77.000 sueldos, y acataba la intervención de sus tres socios, junto a Bertomeu Ros, en el arrendamiento del que él era el clavario ${ }^{42}$. En agosto, Joan Alegre traspasaba al mercader Nicolau Montell alguna de sus participaciones en ambos impuestos, el de la carne y el del Almudín, como hizo Martí con los Bou. Entre los cuatro impuestos, la sociedad había invertido 461.177 sueldos y el número de parçoners de este entramado empresarial ascendía a nueve personas más los ocho maestros artesanos que, en uno de los arrendamientos, cumplían la función de pequeños inversores y, probablemente, de recaudadores.

La tendencia a la concentración de las rentas públicas en manos de un grupo de hombres de negocios, implicaba la disponibilidad de grandes inversiones de capital. En el caso antes citado, Joan Alegre invertiría más de 3.200 libras, Francesc Martí, cerca de 4.200, mientras que Pere Borràs y Francesc Siurana, superaban las 4.600 y 5.100 libras respectivamente. Una cifra considerable si tenemos presente que no era el único negocio empresarial que llevaban a cabo y que, muy al contrario, estas empresas mercantiles valencianas se caracterizaban por la diversificación de la inversión. Por eso, el acaparamiento de los arrendamientos públicos obligaba a los componentes de estas sociedades arrendatarias a buscar entre las élites mercantil y política de la ciudad inversores a los que transferir parte de la propiedad del arrendamiento, inversores que estaban alejados de la gestión y a los que se reembolsaba un beneficio proporcional.

La normativa legal del reino había tratado de limitar el número de socios integrantes de la sociedad arrendataria de impuestos. En concreto, la legislación municipal de 1374, a fin de "esquivar que les imposicions d'aquella no puxen ésser de preus ne de condició pejorades", establecía que la composición de una compañía debía limitarse a un máximo de seis personas "entre principals compradors e parçoners tant solament e no més, mes menys si $\cdot s$ volran" ${ }^{3}$. Esta limitación máxima del número de socios también se exigía en los arrendamientos de impuestos de otras instituciones, por ejemplo de la Diputación del General ${ }^{44}$, y podría interpretarse como un mecanismo para preservar estos negocios a hombres de negocios más pudientes que dispusieran de mayores capitales. Sin embargo, esta normativa era incumplida, quizás porque el número de personas interesadas en estos negocios era más elevado y no había interés por competir, quizás porque no estaban dispuestas a asumir tantos riesgos y preferían fraccionar más la inversión, o porque los comerciantes arrendatarios tenían que dejar participar en los negocios a miembros de la oligarquía política.

421420 , mayo 31, julio 11 (2), agosto 2 (2), 13 y 14 (Ibid., $\mathrm{n}^{\circ} 2.421$ ).

43 1374, diciembre 15 (AMV, Manuals de Consells, A-16, f. 240). La confrontación de la documentación notarial privada, donde sí se explicitan esos reconocimientos con mayor frecuencia, con los asientos contables de los clavarios demuestra que, en la mayor parte de los casos, los avalistas que las autoridades municipales exigían a cada arrendatario de un impuesto solían ser los componentes de la sociedad arrendataria y, entre ellos, estaba el verdadero arrendatario principal del impuesto.

44 María Rosa Muñoz Pomer, Orígenes de la Generalidad..., p. 225. 


\section{La sociedad arrendataria de los impuestos municipales (1441-1447)}

En la subasta de los impuestos de 1441, Gabriel Rojals se hizo conjuntamente con los de la mercancía y el vino por un precio global de 310.000 sueldos, teniendo como avalistas a los mercaderes Joan Alegre y Vidal de Riusec ${ }^{45}$. Meses después, a través de un contrato notarial, reconocía que la adquisición de la imposición de la mercancía por la que había ofrecido 277.000 sueldos la había realizado por cuenta del mercader Joan Alegre, admitiendo con ello su condición de testaferro. Durante las décadas anteriores, Alegre había conseguido el arrendamiento de ese impuesto municipal ${ }^{46}$. Además, Alegre fue desde 1440, y durante los años siguientes, el arrendatario, junto a Gabriel Rojals, de todas las generalidades del reino ${ }^{47}$. En los días siguientes, Alegre aceptaba la intervención de otros parçoners en el arriendo de la imposición de la mercancía: Daniel Barceló, Miquel Andreu, Lluís Blanch ${ }^{48}$, Joan d'Eixarch, caballero, su hermano Galceran, y Gabriel Carbonell se convertían en sus socios, adquiriendo diferentes partes de setzenes.

Era el comienzo de la formación de un entramado enmarañado de intereses empresariales. Al mismo tiempo que Alegre constataba la participación de sus nuevos socios, Vidal de Riusec $^{49}$, que había recurrido también al mercader Gabriel Rojals como testaferro para

\footnotetext{
45 1441, mayo 29 (AMV, Protocols Notarials, no 24-3, J. Beneï).

46 La actividad de Alegre en este mercado era ya frecuente, al menos, entre 1414 y 1417. Su presencia sería permanente en los años posteriores, casi siempre como arrendatario de la misma imposición, cuyas setzenes intercambiaría con sus socios. De los años que tenemos información: 1418 (imposición de la mercaderia); 1420 (socio en las del corte de paño, la carne, el vino y el Almudín); 1426, 1427 (avalista en la de la mercaderia; y 1431, 1432, 1433, 1436, 1437, 1439 y 1440 (arrendatario de la misma). Las referencias archivísticas son: 1418, mayo 24 (ARV, Protocols, $\mathrm{n}^{\circ} 2.419$, V. Saera); 1420, mayo 31, julio 11, agosto 2 (2) y 14 (Ibid., $\mathrm{n}^{\circ}$ 2.421); 1426, mayo 6 y 1427, mayo 20 (AMV, Protocols Notarials, 24-1, Antoni Pasqual); 1431 (AMV, Claveria comuna, O-14): 1432 (Ibid., O-15); 1433 (Ibid., O-16); 1436 (AMV, Claveria de Censals, N-18); 1437, mayo 15 (4) y 30 (ARV, Protocols, $\mathrm{n}^{\circ}$ 2.774, V. Saera); y AMV, Claveria comuna, O-17); 1439, mayo 20 (AMV, Protocols Notarials, 24-3, J. Beneï); y 1440, mayo 18 (ARV, Protocols, $\mathrm{n}^{\circ}$ 4.391, V. Saera).

47 Los primeros contratos notariales de la gestión de este arrendamiento se hallan en: 1439, diciembre 11 (2), 14 (Ibid., $\mathrm{n}^{\circ}$ 2.435, V. Saera); 1440, enero 4, 7 (2), 15, febrero 1, 4, marzo 8, mayo 19 (Ibid., no 4.391); y 1441, enero 2 (Ibid., $\mathrm{n}^{\circ} 2.411$ ).

48 La actividad arrendataria de este comerciante se ciñe a años más recientes: 1430 (avalista del impuesto del corte de paño); 1431 (arrendatario principal de la imposición sobre exportación de pescado); 1435 (lo mismo); 1439 (avalista en las imposiciones del paño de oro y seda y del paño foráneo). La información procede de AMV, Claveria comuna, O-13 (1430); Ibid., O-14 (1431); Ibid., O-17 (1435); y 1439 (AMV, Protocols Notarials, 24-3).

49 Registramos la actividad financiera del mercader converso Vidal de Riusec en este mercado de arrendamientos, casi siempre concentrado en el del vino, desde 1415 (vino) y se prolonga en los años 1423 (paño de oro y seda), 1427 (carne y trigo), 1429 (trigo), 1430 (vino y panaderos), 1431 (trigo), 1432 (los dos del trigo, como avalista junto a su hermano Gabriel de Riusec), 1434 (vino), 1440 (avalista de siete impuestos). Las referencias corresponden a 1415, enero 5 (ARV, Protocols, $n^{\circ}$ 2.416, V. Saera); 1423, julio 8 (Ibid., $\mathrm{n}^{\mathrm{o}}$ 2.422); 1427, mayo 20 y 31 (AMV, Protocols Notarials, 24-1, A. Pasqual); 1429, noviembre 15 (ARV, Protocols, $\mathrm{n}^{\mathrm{o}} 2.426$, V. Saera); 1430, mayo 24 y octubre 6 (AMV, Claveria comuna, O-13); 1431, abril 30 (Ibid., O-14); 1432, mayo 9 y 12 (Ibid., O-15); y 1434, mayo 12 (ARV, Protocols, nº 2.433, V. Saera); 1440 (AMV, Claveria comuna, O-20).
} 
arrendar la imposición del vino por 33.000 sueldos, aceptaba la intervención en el contrato de Joan Alegre y Miquel Andreu ${ }^{50}$. Éste, a la vez que había comprado la imposición del corte de paño por 91.000 sueldos, utilizando como testaferro al mercader Miquel Calcena del que era avalista, reconocía la participación de Joan Alegre y Daniel Barceló. También a través de la intermediación de Calcena, Miquel Andreu se había hecho con la imposición del trigo y la harina que se cobraba a panaderos, harineros y hosteleros por 45.000 sueldos. Además, Calcena había arrendado las imposiciones del Almudín por 50.000 sueldos y las dos del pescado por 35.000 sueldos, por cuenta de Daniel Cornet, también avalista suyo ${ }^{51}$. Por su parte, Gabriel Carbonell, junto a su hermano Joan, había subarrendado varias filloles de la imposición de la mercadería ${ }^{52}$. Por tanto, a través de un mecanismo societario bastante simple, el reconocimiento de participaciones, este pequeño grupo de mercaderes, integrado por nueve personas, gestionaría conjuntamente la mayor parte de todos los impuestos de la ciudad, por un valor total de 531.000 sueldos. Solo quedaban fuera de su control la imposición de la carne, que era colectada directamente por el municipio, y las del paño de oro y seda y del paño foráneo que, conjuntamente, habían sido arrendadas por el mercader Bernat Pelleja, avalado por el florentino Clemente di Zumaya, quien era el verdadero arrendatario ${ }^{53}$. En todos los casos, el propietario principal del arrendamiento del impuesto cumplía la función de clavario del mismo.

Carentes de documentación notarial privada para 1442, la contabilidad municipal y las escrituras de los escribanos del Consell permiten intuir la continuidad de la sociedad. Joan Alegre figura como avalista del arrendamiento del impuesto de la mercaderia obtenido por Pere Masella, que actuaría de testaferro, y Miquel Andreu de los impuestos de los panaderos, del corte de paño, de los paños de oro y seda y del paño foráneo que habían sido arrendados por el comerciante Joan Solanes. Además, Vicent Fortuny había arrendado otros tres impuestos: el del vino y los dos del pescado ${ }^{54}$. Reconoció haber comprado el primero por cuenta de Vidal de Riusec, y los otros para Daniel Cornet. En total, otros siete arrendamientos por un valor total de 559.950 sueldos. A principios de 1443, los miembros de la sociedad todavía estaban intercambiando partes de los arrendamientos. Daniel Cornet reconocía como parçoners a Joan Alegre,

\footnotetext{
50 Andreu debía ser un mercader de la segunda generación del siglo. Su actividad comienza a reflejarse de manera episódica en la documentación notarial en la década de 1430, y su intervención en este mercado no ha sido detectada hasta 1440 actuando como avalista en el arrendamiento de los siete impuestos adquiridos por el testaferro Miquel Calcena (AMV, Claveria comuna, O-20). Unos años antes había participado junto a Joan Alegre como arrendatario de todos los capítulos de las generalidades de 1435 (1435, octubre 27. ARV, Protocols, $\mathrm{n}^{\circ} 2.433$ ), actividad que mantendría en los años siguientes.

51 La participación de Cornet se circunscribe a la década de 1430, más tardía respecto a sus negocios mercantiles perceptibles desde la anterior. La documentación hallada se limita a los años 1432 y 1433 (avalista en el paño foráneo), y 1440 (avalista en siete arrendamientos). Las referencias son 1432 (AMV, Claveria comuna, O-15), 1433 (Ibid., O-16) y 1440 (Ibid., O-20).

52 Este grupo de contratos notariales se redactó el mismo día (1441, septiembre 14. ARV, Protocols, $\mathrm{n}^{\circ}$ 2.411, V. Saera).

53 1443, marzo 13 (Ibid., $\mathrm{n}^{\mathrm{o}}$ 796, M. Doto).

54 1442, abril 13, 14, 16 (2), 17 y 30, mayo 4, 30 y junio 5 (2) (AMV, Protocols Notarials, 24-3, J. Beneï); y 1442 (AMV, Claveria comuna, O-21).
} 
Miquel Andreu y Vidal de Riusec, quien a su vez aceptaba como copartícipes a Daniel Barceló, Gabriel de Riusec, Vicent Granollers, Martí Roís ${ }^{55}$, Alí Xupió y Mahomat Ripoll ${ }^{56}$. A su vez, Miquel Andreu aceptaba como socio en sus impuestos a Vidal de Riusec. Por su parte, Joan Alegre admitía como parçoner al caballero Joan d'Eixarch ${ }^{57}$. En los años siguientes, la red tendida por esta élite financiera en torno a la gestión de las rentas municipales se haría cada vez más tupida. En el mes de julio de 1443, Joan Solanes, arrendatario de la imposición de los paños de seda y oro y de los paños foráneos, aceptaba la propiedad del arriendo a Vidal de Riusec. Lo mismo que haría Salvador Gençor con el arrendamiento del impuesto de los doce dineros del Almudín. Vidal de Riusec había obtenido también la imposición del vino, utilizando como testaferro a Joan Asensi. Por su parte, Guillem Gasó, arrendatario del tall de drap de lana, admitía haber obrado por cuenta de Lluís Blanch, el verdadero propietario del arriendo y uno de sus avalistas. Blanch, ese mismo día, reconocía la participación en el capítulo de Daniel Cornet, Vidal Riusec et aliorum sociorum. Vidal de Riusec escrituraba la participación en el arriendo del impuesto del vino a Joan d'Eixarch ${ }^{58}$. El resto de arrendamientos, excepto el de la carne que recolectaba directamente la ciudad, fueron comprados por el mercader Guillem Trilles, teniendo como avalistas a Daniel Cornet, Joan d'Eixarch y Vicent Alegre, principalmente, por lo que probablemente actuaba como testaferro y la recaudación de esos impuestos acabó en manos de la misma sociedad. El acaparamiento de los nueve impuestos que se arrendaban en aquel momento suponía una inversión global de 628.100 sueldos.

Cuando a partir de mayo del año siguiente se arrendaron los impuestos municipales, este grupo de comerciantes volvió a acumular negocios. Daniel Cornet adquirió a través de un testaferro a quien avalaba, el mercader Antoni Pujol, la imposición del trigo del Almudín por 53.000 sueldos, y por medio de Guillem Trilles, la de los dos pescados por 33.600 sueldos. Vidal de Riusec, por medio de Miquel Calcena, compraba el arriendo del impuesto de la mercancía por 310.600 sueldos; a través de Salvador Gençor, el del vino por 43.200 sueldos; y empleando a Bernat Bosch, un pelaire, el impuesto de los panaderos por 46.000 sueldos. Lluís Blanch, utilizando también como intermediario a Miquel Calcena, adquiría la imposición del consumo de paños de lana por 105.000 sueldos. Joan Alegre, empleando también a Calcena y respaldado por el aval de Lluís Blanch, Vidal de Riusec y Joan Figuerola, había arrendado el impuesto de los paños de oro y seda y la entrada de paños foráneos por 25.000 sueldos. Dejando aparte la imposición de la carne, que seguía

\footnotetext{
55 Enrique Cruselles Gómez, "Historias de vida en la persecución inquisitorial: la familia Roís en Valencia, 1417-1519”, En el primer siglo de la Inquisición española. Fuentes documentales, procedimientos de análisis, experiencias de investigación, José María Cruselles Gómez (coord.), Universitat de València, València, 2013, pp. 295-316.

56 Suegro y yerno eran los principales representantes de la élite mercantil de la aljama mudéjar valenciana (Manuel RuZAFA GARCía, “Alí Xupió, senyor de la moreria de València”, L'univers dels prohoms, Rafael Narbona Vizcaíno (coord.), Edicions 3i4, València, 1995, pp. 137-173).

57 1443, marzo 1 (2) y 6 (ARV, Protocols, no 796, M. Doto).

58 1443, julio 12 (5) (Ibid.).
} 
siendo recaudada por la ciudad a través de Pere Maiques, todos los gravámenes habían quedado en manos de este grupo de comerciantes por un valor total de 617.000 sueldos $^{59}$. Días después se sucedieron los contratos con objeto de intercambiar las partes de propiedad de los diferentes arrendamientos y que permitirían imbricar los destinos de las diferentes empresas mercantiles y estrechar los lazos de cohesión del grupo de arrendatarios. Vidal de Riusec participaba con diez desetenes y media en la imposición arrendada por Alegre. A su vez, Riusec reconocía que Daniel Cornet poseía seis setzenes y media en la de la mercancía, cinco y media en la del trigo y harina de los panaderos y otras cinco y media en la del vino. Cornet también participaba con seis setzenes y media en la imposición del tall del drap arrendada por Lluís Blanch. Por su parte, Cornet certificaba que Vidal de Riusec poseía diez setzenes y media en la del trigo del Almudín, y nueve y media en la del pescado seco y salado. Además, Cornet confirmaba que en todos los arrendamientos en los que poseía participaciones, tanto los contratados directamente por él como los realizados por Vidal de Riusec, Joan Alegre participaba en todos y cada uno de ellos con tres setzenes. Joan Alegre le devolvía el detalle, haciendo partícipe a Cornet con dos setzenes y media en la imposición del paño de oro y seda. Por su cuenta, Lluís Blanch vendía tres desetenes y media a Vidal de Riusec en el impuesto del tall del drap, acción que era correspondida por Riusec haciendo propietario a Blanch con dos setzenes en las imposiciones del trigo del Almudín, del trigo de panaderos, del vino y del pescado seco y salado, y con tres desetenes en el tall del paño de oro y seda y de los paños foráneos. Desde ese momento, cuando ya se habían entrelazado las inversiones de estos empresarios, los acuerdos siguientes atrajeron el resto de capitales entre un grupo secundario de inversores. El notario Francesc Escolà, hombre muy integrado en la vida pública del municipio, compró a través de Riusec dos setzenes o desetenes, dependiendo del impuesto, en todos los capítulos contributivos del municipio. Al mismo tiempo, Blanch hizo partícipe al notario con dos desetenes o setzenes en las participaciones que poseía en todos los impuestos de la ciudad. También Alegre hizo copartícipe a Gabriel Carbonell con una setzena o desetena y media en las partes que poseía en todos los impuestos. Así mismo, Lluís Blanch vendía a Joan Figuerola, noble, antes mercader, dos desetenes y media en la imposición del tall del drap. Además, Riusec vendía a Joan Figuerola dos setzenes o desetenes de los títulos que poseía en todos los impuestos. Por tanto, con las nuevas incorporaciones, el arrendamiento de los impuestos municipales de Valencia era controlado por un grupo de siete personas, de los cuales realmente sólo Joan Alegre, Daniel de Cornet, Lluís Blanch y Vidal de Riusec ("tanquam emptores et parçonerios omnium capitulorum imposicionum civitatis Valencie") tenían control sobre la organización de la sociedad arrendataria, pues eran los que de común acuerdo fijaron el salario de los clavarios en 700 libras, distribuyéndolas entre Francesc Escolà, Daniel Cornet y Vidal de Riusec ${ }^{60}$.

1444, mayo 7, 11, 1218 y 26 (AMV, Protocols Notarials, 24-5, J. Beneït).

60 1444, junio 15 (3), julio 6 (10) y julio 10 (4) (ARV, Protocols, no 798. M. Doto). 
Hay poca documentación notarial para el año 1445, aunque la institucional advierte ya de ciertos cambios. Algún testaferro ya había actuado en años anteriores. Miquel Calcena se hacía con el arrendamiento del corte de paño de lana. Tras él, como avalista, estaba Lluís Blanch, que se convirtió en el principal arrendatario, distribuyendo partes entre Joan Alegre, Vicent Granollers, el caballero Joan Figuerola, Alí Xupió y un socio nuevo, el mercader Pere de Montblanc. El comerciante Lluís de Conca obtuvo en la subasta varios arrendamientos: la mercancía y las dos imposiciones sobre el pescado. Detrás tenía como avalistas al notario Francesc Escolà y al doctor en leyes Gabriel de Riusec, hermano de Vidal, que también avalaban el arrendamiento del trigo del Almudín hecho por Salvador Gençor. Este mercader se hizo asimismo con el impuesto aplicado a los panaderos, avalado por Bernat Moltó alias Andreu, hermano de Miquel, y Pere Igualada. Sin embargo, los otros arrendamientos parecen escapar a la sociedad. Lluís del Cid, un campesino, arrendaba la imposición del vino; y el mercader Jaume Clariana, las del paño de oro y seda y del paño foráneo ${ }^{61}$.

Los arrendamientos de 1446 confirman la tendencia marcada en el año anterior. Los tres impuestos de los paños fueron contratados por un grupo ajeno, donde destacaba el comerciante Joan Amat, que prolongaría su actividad en años posteriores. También la imposición del vino fue avalada por comerciantes ajenos a la anterior sociedad, Lluís de Santàngel y Lluís de Conca, principal arrendatario. Francesc Escolà, Bernat Moltó alias Andreu, Antoni Pujol y Pere Igualada respondían por los arrendamientos de la mercancía, los dos del pescado y los del trigo. De ellos, Pujol, que hasta entonces había participado como testaferro, se convirtió en el principal arrendatario de la imposición de los doce dineros del Almudín, y aceptaba como socio a Lluís Blanch con ocho setzenes ${ }^{62}$.

Los datos obtenidos en los contratos de 1447 confirman el relevo generacional que se estaba produciendo en el mercado. Vidal de Riusec había fallecido en 1445. También, desde ese mismo año, Joan Alegre había abandonado todo negocio y fallecería en los años siguientes, como el mercader Daniel Cornet. En 1447, los principales sistemas arancelarios -tanto el real, como el de la Diputación del General, y el de la ciudad- fueron monopolizados por el mismo grupo de mercaderes. A principios de año, Lluís Bou arrendó el derecho de peaje, formalizando la participación de un amplio número de parçoners: Vicent Granollers, Pere d'Amiga, Martí Roís, Joan d'Eixarch, Pere de Montblanc, Daniel Barceló, Joan Figuerola y Jaume d'Esplugues. Con posterioridad, Bou reconocía la participación de Amoreto de Donino y Bernat Guillem de Reig en sus setzenes. En las mismas fechas, Lluís Bou adquiría también el arrendamiento de las generalidades de ese año, creando para ello una

${ }_{61}$ 1445, abril 26 (2), 27 (2), 29, mayo 5 y 10 (AMV, Protocols Notarials, 24-4, J. Beneï); 1445, septiembre 9 (ARV, Protocols, $\mathrm{n}^{\circ}$ 799, M. Doto); 1445, octubre 2, noviembre 8 y 24 (APCCV, protocolo $\mathrm{n}^{\mathrm{o}}$ 25.969, P. Castellar).

62 1446, mayo 12, 13, 14, 17, 21, 25 y 27 (AMV, Protocols Notarials, 24-4, J. Beneït); mayo 28 y julio 27 (ARV, Protocols, $\mathrm{n}^{\circ}$ 800, M. Doto). 
gran sociedad en la que intervenían todos los mercaderes y nobles citados anteriormente, además de Llorens Ballester, Antoni Vilana, Jaume Dezpuig y Joan de Gallach ${ }^{63}$.

En aquel verano, el notario Francesc Escolà conseguía arrendar la imposición de la mercadería por 303.600 sueldos a través de Joan del Cid, incluyendo en la sociedad arrendataria a un grupo conocido de mercaderes: el cambista Jofré de les Escales ${ }^{64}$, Martí Roís, Lluís Blanch, Daniel Cornet y los mudéjares Alí Xupió y Mahomat Ripoll. Por su parte, y a través de Bertomeu Garcia, Bernat Moltó alias Andreu adquirió la imposición de la harina y el trigo de los panaderos, incluyendo en el arrendamiento a Daniel Cornet, Martí Roís, Lluís Blanch, Jofré de les Escales, Alí Xupió y Mahomat Ripoll. Por su lado, Jofré de les Escales, que intervenía en las subastas por medio de un sedero, Francesc Pelegrí, se había hecho con los impuestos de la importación y exportación de pescado seco y salado, haciendo partícipes a un grupo similar de socios: Joan Amat, Daniel Cornet, Lluís Blanch, Martí Roís, Francesc Escolà, Alí Xupió y Mahomat Ripoll ${ }^{65}$. En los contratos de arrendamiento, Joan Amat figura asimismo como avalista de los tres impuestos que gravaban la venta de paños, arrendados por Joan del Cid. Por su parte, Pere de Montblanc y Antoni Pujol garantizaban con su patrimonio los arrendamientos de las imposiciones del vino y del Almudín hechas por el cuchillero Pere Martínez ${ }^{66}$. Un nuevo grupo de arrendatarios, unidos por los mismos lazos de solidaridad financiera, se formaba entonces, integrándose con los supervivientes de la generación anterior, que pasaban a ocupar posiciones menos activas en la trama empresarial, resultado de la promoción social que habían experimentado a lo largo de esa época.

Poca documentación ha sobrevivido en la actualidad que permita evaluar la rentabilidad de los negocios de los arrendamientos de impuestos municipales. A principios de 1443, el mercader Joan Alegre reconocía recibir de Miquel Andreu 271 libras y 8 sueldos en concepto de beneficios aportados por las nueve setzenes que poseía en el impuesto de los panaderos y de otras tantas que tenía en el de los paños de lana del año fiscal 1441. Si el valor conjunto de estos dos arrendamientos ascendía a 136.000 sueldos, esos beneficios rondaban el 7\% de la inversión. A su vez, Miquel Andreu había obtenido 161 libras y 5 sueldos por las tres setzenes que poseía en la imposición de la mercaderia, arrendada por 277.000 sueldos, es decir, un 6,2\% del capital aportado ${ }^{67}$. En ambos casos se incluía en esas cantidades el salario percibido por los trabajos de gestión contable.

\footnotetext{
63 1447, enero 21 (3) 29 (APCCV, protocolo nº 25.974, P. Castellar).

64 Si no se trata de un hijo homónimo, la longevidad de este mercader y cambista es asombrosa, comparable a la de Daniel Barceló, Vidal de Riusec o Joan Alegre. Ya fue socio de ellos en la sociedad arrendataria de las imposiciones en 1414, pero después desaparecería del mercado, reapareciendo cuando sus viejos compañeros llegaban al final de sus días. Las referencias son: 1414, junio 13 (ARV, Protocols, $\mathrm{n}^{\circ} 2.415$, V. Saera); 1416, enero 8 (Ibid., no 2.417); 1417, febrero 20 (2), abril 14 y 22 (2) (Ibid., n 2.418).

65 1447, julio 5, agosto 25 (3), 28 (2) y 29 (Ibid.).

66 1447, mayo 2, 4, 10, 15 y 23 (AMV, Protocols Notarials, 24-4, J. Beneït).

67 1443, febrero 15 (ARV, Protocols, $\mathrm{n}^{\circ}$ 796, M. Doto). Aunque los beneficios personales de Alegre fueron menores por cuanto, a su vez, pagó al caballero Joan Figuerola 98 libras y 5 sueldos por la parte inconcreta - no reconocida por otra documentación-que tenía en todas las setzenes de diferentes impuestos compradas por Alegre, que afectaba al menos a siete arrendamientos (1443, marzo 1. Ibid.).
} 
En ese mismo año fiscal, el florentino Clemente di Zumaya había arrendado, a través de un mercader testaferro, Bernat Pelleja, los impuestos del paño de oro y de seda y de la entrada de paños foráneos por 20.100 sueldos, donde Zumaya actuaba como avalista junto al corredor Francesc del Bosch. Años más tarde, a principios de 1443, Zumaya, convertido en clavario del arrendamiento, reconocía cobrar de Bosch, 7 libras, 2 sueldos y 6 dineros por las pérdidas sufridas ${ }^{68}$. Dado que el corredor poseía dos setzenes, el quebranto correspondía al 5,6\% de la compra realizada.

El caballero Joan Figuerola poseía dos desetenes en el arrendamiento del corte de paño de lana de 1443, obtenido por Lluís Blanch al precio de 94.000 sueldos a través de testaferro. En 1448, cuatro años más tarde, tuvo que pagar a su clavario 4 libras, 7 sueldos y 6 dineros por las mermas sufridas, es decir, menos del $1 \%{ }^{69}$. El año siguiente también produjo desasosiego. Joan d'Eixarch, clavario de los arrendamientos de las imposiciones de los panaderos y de la entrada y salida de pescado seco y salado, arrendados por un total de 79.600 sueldos, cobró a los herederos de Daniel Cornet, que poseía media setzena en el primero y tres y media en el segundo, 49 libras, 12 sueldos y 6 dineros por las pérdidas tenidas, que corresponde a casi el 5\% del global de la inversión realizada en los tres impuestos ${ }^{70}$. En la Navidad de 1448, dos árbitros determinaron el detrimento sufrido por dos setzenes del arrendamiento del impuesto de la mercancía de 1444 en 80 libras, 8 sueldos y 10 dineros $^{71}$. Contando que ese impuesto fue arrendado por Vidal de Riusec por 310.600 sueldos, las deudas cobradas por el clavario Joan Figuerola, eso sí, otra vez cuatro años más tarde, suponían poco más del $4 \%$ de la inversión.

Tampoco el año fiscal de 1445 fue especialmente bueno. La parçonerie seu societatis del arrendamiento del impuesto del corte de paño, formada por Lluís Blanch, Joan Alegre, Pere de Montblanc y Joan Figuerola tuvo pérdidas. En 1449, el arbitraje las fijó en 75 libras, que suponía el 1,5\% del precio, 97.000 sueldos $^{72}$. Estos resultados podrían explicar el brusco descenso de los precios de los arrendamientos a partir de 1448, acentuado por la epidemia de 1450 .

\section{Miembros de la oligarquía urbana}

El carácter restringido del grupo de arrendatarios de los impuestos municipales se manifiesta con claridad en el número reducido de socios. Del casi medio millar de comerciantes que debía tener la ciudad en el segundo cuarto del siglo XV, sólo una cantidad superior a la veintena participaba en el arrendamiento de los impuestos municipales, élite profesional de la que sólo una cuarta parte figuraba como titular directa del arrendamiento: Joan Alegre, Daniel Barceló, Miquel Andreu, Vidal de Riusec, Lluís Blanch y Daniel Cornet. Todos ellos eran comerciantes muy activos y conocidos de

68 1443, marzo 13 (Ibid.).

69 1448, diciembre 3 (Ibid., $\mathrm{n}^{\mathrm{o}}$ 801, M. Doto).

70 1449, junio 30 (Ibid., no 803 ).

71 1448, diciembre 24 (Ibid., $\mathrm{n}^{\circ}$ 801).

72 1449, diciembre 31 (APCCV, protocolo no 25.958, P. Castellar). 
la ciudad y sus negocios, caracterizados por la diversificación de actividades, desde la comercialización de mercancías hasta los mercados financieros, incluían tanto el ámbito local como las rutas marítimas europeas. Sin duda, todos ellos pertenecían a la élite del grupo mercantil, los hombres de negocios.

Al mismo tiempo, la mayor parte del grupo había ejercido antes y continuó desempeñando mientras arrendó impuestos locales cargos significativos en la administración municipal. Sin ser demasiado exhaustivos, el listado es esclarecedor. Daniel Barceló, hijo de tendero, fue clavario de la ciudad en 1417, 1418, o 1424; clavario del quitament entre 1431 y 1436; cónsul de mar en 1419; y colector de impuestos en 1438. Además, fue elegido conseller de parroquia en 1412, 1416, 1422 y 1436, cargo también desempeñado por su hermano Francesc en 1419 y 1423. La relación de Lluís Blanch con la oligarquía urbana fue aún más especializada: fue clavari de censals en 1430, 1431, 1436, 1437 y 1438; clavari del quitament entre 1445 y 1447; y clavari de la pecúnia comuna en 1427 y 1428 . Aparte de esta función participó poco más en la vida pública de la ciudad: fue elegido conseller en 1430, 1436, 1433 y 1440. Joan Alegre, un pañero que en la primera década del siglo había cambiado de especialización profesional, tuvo una intensa vida pública al igual que su hijo y heredero, Vicent Alegre. Algunos cargos se limitaban a la función gestora apropiada a los comerciantes (clavari en 1420, tasador del corte de paños en 1424, administrador de los impuestos en 1430, obrer de murs $i$ valls en 1440), pero no sólo los combinaron con otros que reforzaban su condición ciudadana (representante en las cortes de Sagunto en 1428, consellers en la guerra contra Castilla en 1429 y 1430) sino además con algún cargo de primer orden (Joan fue jurado en 1428 y 1435, y Vicent, en 1441 y 1456, y Justicia Criminal en 1446) y un nutrido grupo de elecciones como consellers de parroquia (1416, 1420, 1422, 1429, $1430,1432,1433,1435,1438$ y 1440). Miquel Andreu había oscilado de cargos con un claro matiz gestor (clavari comú, en 1425; administrador de los impuestos, en 1426) a otros de contenido más político (jurado en 1443 y 1448, miembro de los dotze del quitament, en 1444 y 1454; mustaçaf, en 1451) ${ }^{73}$.

La conexión entre el ejercicio del poder público y el arrendamiento de los impuestos municipales se estrecha si se atiende a la presencia pública de los otros socios secundarios de esta sociedad contratista de impuestos públicos. El notario Francesc Escolà, hijo homónimo del que había sido escribano del Consell y síndico de la ciudad desde la segunda década del siglo, pertenecía a la sociedad acomodada de la ciudad ${ }^{74}$. Los Eixarch pudieron, gracias a la amplitud de su entramado familiar y al proceso de promoción social que elevaba a algunos miembros al grupo nobiliario, disfrutar de cargos municipales de manera casi anual durante la primera mitad del siglo. De hecho, a lo

\footnotetext{
73 Salvador Carreres Zacarés, Libre de memòries..., vol. I, pp. 509, 576, 578, 586, 590 y 594. Por ahora, no contamos con datos sobre la presencia de Vidal de Riusec y Daniel Cornet en la administración municipal. Aun así, el hermano del primero, Gabriel de Riusec, doctor en leyes, ocupó algunos puestos significativos: inquisidor de los cargos municipales (1419) o asesor del justicia civil (1422 y 1439) (Ibid., pp. 483,490 y 567$)$.

74 José María Cruselles Gómez, Els notaris de la ciutat..., pp. 246-247.
} 
largo la década de 1430, mientras Galceran d'Eixarch había ejercido las tres claverías, su hermano, el caballero Joan d'Eixarch había alcanzado la juradería. Los miembros de la familia Granollers y Bou disfrutaron de la misma relación intensa con el poder público ${ }^{75}$.

\section{A modo de conclusión: tiempos pasados y venideros}

La consolidación del sistema económico urbano permitió, en el caso de la ciudad de Valencia, la maduración de un sistema fiscal más tardío, ensayado de manera extraordinaria desde antes de mediados del siglo XIV. Al mismo tiempo, la integración de su mercado en la red mercantil europea supuso una intensificación de los flujos de riqueza, el crecimiento de la ciudad y, en consecuencia, el reforzamiento de la función social del comerciante local, al cual se asignaron determinadas obligaciones y privilegios. Sobre todo, se le responsabilizó de la atracción de riqueza sobre la que sustentaba la recaudación fiscal del municipio. Asimismo, se dejó en sus manos la capitalización del sistema de arrendamiento de los impuestos municipales. En contrapartida, el municipio apoyó con subvenciones financieras y protección militar y jurídica la actividad del comerciante local. Incluso aceptó prácticas empresariales que, como mínimo, generaban opacidad sobre los procedimientos administrativos, por ejemplo, el recurso habitual a testaferros que dificultaba la identificación de los componentes de las empresas arrendatarias, solo reconocibles en los protocolos municipales como fiadores de los arrendamientos, claramente identificados en los protocolos privados cuyas páginas se custodiaban de miradas ajenas.

A lo largo de las décadas comprendidas en la primera mitad del siglo XV, los grandes comerciantes locales supieron actualizar modelos contractuales con los que fueron tejiendo un tupida red empresarial que acabaría permitiendo el acaparamiento de los negocios que el municipio procuraba en torno a la subasta de los arrendamientos de los impuestos municipales. Una treintena de mercaderes, poco más, acabó acaparando durante la mayor parte de aquel periodo la recaudación de los diez impuestos indirectos que gravaban el mercado urbano. Comerciantes cuyo currículum profesional revela, por un lado, la diversificación e internacionalización de sus negocios, por lo que la participación en estas sociedades arrendatarias no era más que una de sus posibles actividades, y no precisamente ni la más lucrativa ni la más llamativa, y por el otro la combinación de su profesión con una presencia frecuente en las instituciones municipales, generalmente en cargos de tipo técnico, que explican la connivencia de intereses de este grupo de mercaderes con la oligarquía ciudadana que facilitaba sus negocios. De hecho, miembros de esa élite social terminarían participando de aquellos negocios y convirtiéndose en socios de los comerciantes locales.

La reconstrucción de la evolución de los precios de los arrendamientos de los impuestos municipales durante gran parte de la primera mitad del siglo XV, permite constatar que la constitución de esa red empresarial que acaparaba los arrendamientos en las subastas

75 Enrique Cruselles Gómez, Los mercaderes de Valencia en la Edad Media (1380-1450), Editorial Milenio, Lleida, 2001, pp. 301, 303-304 y 307-308. 
públicas coincidió en el tiempo con una tendencia decreciente de los precios de los arrendamientos. Coincidencia que se producía en un época en que el crecimiento económico, mediante la integración internacional del mercado valenciano, fundamentaba el enriquecimiento de los hombres de negocios y su promoción social y, en general, favoreció una etapa de esplendor de la capital del reino.

Esta asociación de arrendatarios seguiría gestionando la recaudación de los impuestos municipales superado el ecuador de la centuria. Sin embargo, a partir de aquel momento se aprecia la concurrencia de algunas tendencias, confirmadas a finales de aquella época, que conllevarían un cambio sustancial del sistema de arrendamiento de los impuestos municipales en la segunda mitad de siglo, y que aconseja posponer su estudio para otro lugar: por un lado, el predominio de prestigiosos hombres de negocios comenzó a diluirse en esos años con la participación más activa de miembros de la oligarquía municipal; además, el procedimiento de subasta concentró aún más los capítulos de los impuestos, favoreciendo el acaparamiento; $y$, finalmente, el precio de los arrendamientos invirtió su tendencia descendente.

Fecha de recepción: 4 de octubre de 2016

Fecha de aceptación: 10 de noviembre de 2016 